\title{
Lucas Champollion* \\ Stratified reference: the common core of distributivity, aspect, and measurement
}

DOI 10.1515/tl-2015-0008

Abstract: Why can I tell you that I ran for five minutes but not that I ${ }^{*}$ ran to the store for five minutes? Why can we talk about five pounds of books but not about *five pounds of book? What keeps you from saying *sixty degrees Celsius of water when you can say sixty inches of water? And what goes wrong when I complain that ${ }^{*}$ all the ants in my kitchen are numerous? The constraints on these constructions involve concepts that are generally studied separately: aspect, plural and mass reference, measurement, distributivity, and collectivity. This paper provides a unified perspective on these domains and gives a single answer to the questions above in the framework of algebraic event semantics.

Keywords: algebraic semantics, aspect, boundedness, collectivity, distributivity, mass, measurement, mereology, monotonicity, plural, partitives, telicity

\section{Introduction}

This paper presents a theory that builds connections between three domains which are often addressed separately: aspect, measurement, and distributivity. I aim to provide a synthesis of several previous and novel ideas in the unifying framework of algebraic event semantics. I suggest that a number of phenomena in these domains can be connected in this framework through a novel higherorder property, stratified reference. This property is both general enough to connect and subsume familiar notions, and formally precise enough to transfer theoretical insights across the literature.

This paper extends and builds on algebraic semantic work on the close parallels between the nominal and verbal domains, such as Link (1983), Bach (1986) and Krifka (1998). Stratified reference pulls together several semantic oppositions closely associated with the domains under consideration. These are the singular-plural and count-mass oppositions in the nominal domain; the intensive-extensive opposition in the domain of measurement; and in the verbal domain, the telic-atelic opposition, the collective-distributive opposition,

*Corresponding author: Lucas Champollion, Department of Linguistics, New York University, 10 Washington Pl, New York, NY 10012, USA, E-mail: champollion@nyu.edu 
and what I will call the numerous-gather opposition, which involves different kinds of collective predicates.

Singular, telic, and collective predicates are delimited or bounded in ways that plural, mass, atelic, and distributive predicates are not. This raises the question how to formally characterize the difference between the two concepts boundedness and unboundedness. Answering this question amounts to specifying what property a predicate needs to have in order to qualify as atelic, distributive, plural, or to have mass reference. It is not obvious that there should be a single property that is shared by all these predicates. I will show, however, that it is indeed possible to isolate such a property. The identity of this property can be determined by analyzing a number of nominal and verbal constructions which are sensitive to the semantic oppositions in question, and which are central to the study of aspect, measurement, and distributivity. Some examples of these constructions are for-adverbials, which distinguish atelic from telic predicates (1); pseudopartitives, which distinguish plurals and mass nouns from singular count nouns (2); the word each, which distinguishes distributive from collective predicates (3); and the word all, which distinguishes between two classes of collective predicates that can be roughly characterized as involving collective action versus cardinality checks (4). I refer to these constructions collectively as distributive constructions.

(1) a. John ran for five minutes.

atelic

b. *John ran to the store for five minutes.

${ }^{*}$ telic

(2) a. thirty pounds of books

plural

b. thirty liters of water

mass

c. *thirty pounds of book

${ }^{*}$ singular; ok as coerced mass

(3) a. The boys each walked.

distributive

b. The boys each met.

${ }^{*}$ collective

(4) a. All the boys gathered in the hallway.

collective action

b. *All the boys were numerous.

${ }^{*}$ cardinality check

The main claim of this paper is that these constructions all exclude bounded predicates through stratified reference, a higher-order property (a property of predicates) that is parametrized in order to account for the differences between the constructions in question. Stratified reference requires a predicate that holds of a certain entity or event to also hold of its parts along a certain dimension and 
down to a certain level of granularity. Dimension and granularity are understood as parameters which different distributive constructions can set to different values.

The dimension parameter specifies the way in which the predicate in question is distributed. Different settings of this parameter allow one and the same predicate to be atelic but not distributive, for example, or vice versa. When the dimension parameter is set to time, stratified reference applies to atelic but not to telic predicates, as in (1). When it is set to a measure function like weight or volume, stratified reference applies to mass and plural nouns but not to count nouns, as in (2). When it is set to a thematic role like agent, stratified reference applies to distributive but not to collective predicates, as in (3), or to certain kinds of collective predicates but not others, as in (4).

The granularity parameter specifies the size of the parts in question as measured along the relevant dimension. Depending on how it is set, the parts in question must typically be either mereological atoms (singular entities) or else very small in size. This parameter accounts, among other things, for the differences between distributive constructions over discrete (count) domains, such as each and all constructions, and those over domains involving continuous dimensions, such as for-adverbials and pseudopartitives.

The names dimension, granularity, and-as I will explain later-stratified reference are derived from a visual metaphor, which is based on the idea that individuals, substances, and events occupy regions in an abstract space. The dimensions of this space include the familiar spatial and temporal dimensions as well as any measure functions and thematic roles that happen to be defined for the entity in question. To understand a thematic role as a dimension, assume that the individuals that correspond to these roles are ordered in an arbitrary but fixed way.

To give a few examples, an object whose weight is large corresponds to a region with a large extent along the weight dimension. An event whose agent is a plural entity corresponds to a region with a large extent along the agent dimension, while an event whose agent is singular corresponds to a region which is not extended along the agent dimension at all. A temporally and spatially punctual event whose thematic roles are all singular entities corresponds to a point. A temporally and spatially punctual event that has plural entities as its agent and theme and singular entities as its other thematic roles corresponds to an infinitely thin rectangle that is extended along the agent and theme dimensions.

Section 2 introduces stratified reference and shows how it characterizes the opposition between atelic and telic predicates, both in time and space. Section 3 uses stratified reference to characterize several oppositions that are relevant in pseudopartitives, including those concerning singular and plural predicates, count and mass predicates, and different kinds of measure functions. Section 4 
uses stratified reference to formulate meaning postulates that characterize the difference between distributive and collective predicates, and differences within the class of collective predicates. The paper closes with a discussion of open problems and possible avenues for further research.

\section{Aspect}

In this section I introduce and motivate stratified reference, and I show how it can be used to characterize the telic/atelic opposition. This opposition is linguistically relevant because it is needed in order to describe the behavior of a number of aspectually sensitive constructions. The best-known examples of these constructions are measure adverbials, such as for-adverbials, which are compatible with atelic predicates but not with telic predicates, setting coercion and reinterpretation aside (Vendler 1957):

(5) a. John walked for five minutes.

atelic

b. ${ }^{\star} J o h n$ walked to the store for five minutes.

telic

For-adverbials are usually contrasted with in-adverbials. In neutral contexts, they are compatible with telic predicates but not with atelic predicates:

(6) a. John walked for five minutes.

b. ${ }^{\star} J o h n$ walked in five minutes.

These are not the only aspectually sensitive adverbials. For example, until is also sensitive to the atelic-telic distinction (Karttunen 1974; Hitzeman 1991, 1997).

(7) a. John ate away at his sandwich until Mary arrived. atelic b. \#John finished his sandwich until Mary arrived. telic

Similar generalizations have been suggested to underlie the behavior of French adverbial beaucoup ("a lot”, Doetjes 2007) and also of German seit ("since"), although its interaction with the Perfect makes this more difficult to observe (von Stechow 2002).

While most discussions of aspect focus on its interaction with tense and time, measure adverbials can be temporal as well as spatial (Moltmann 1991; Gawron 2005). Spatial for-adverbials test for a spatial counterpart of atelicity but work analogously to temporal for-adverbials otherwise. For example, the predicate meander is spatially atelic because, roughly speaking, every part of a 
meandering road itself meanders (so long as it is not too small; I come back to this point below). For this reason, it is compatible with spatial for-adverbials but not with spatial in-adverbials:

(8) a. The road meanders for a mile.

b. *The road meanders in a mile.

(cf. Gawron 2005)

As another example, (9a) has a stative interpretation on which it describes a crack whose width gradually increases over a stretch of five meters. By contrast, example (9b) cannot mean that the crack gradually widens by $2 \mathrm{~cm}$ over a stretch of five meters. It only has an irrelevant interpretation on which the crack's width over a stretch of five meters is $2 \mathrm{~cm}$ more than elsewhere, which arguably corresponds to result-oriented interpretations of for-adverbials like The Sherriff jailed Robin Hood for four years.

(9) a. The crack widens for $/ \star^{\star}$ in 5 meters.

spatially atelic

b. The crack widens $2 \mathrm{~cm}$ in/ ${ }^{\star}$ for 5 meters.

spatially telic

Some other adverbials also behave like spatial for-adverbials, as shown in the examples in (10) from Moltmann (1991).

(10) a. Worldwide children/\#a child/\#1000 children suffer(s) from hunger.

b. Throughout the country the increased air pollution caused protests /\#a protest/\#the protests.

From this and similar examples, I conclude that spatial for-adverbials test for a spatial counterpart of atelicity. The following minimal pair shows that spatial and temporal for-adverbials give rise to different interpretations, as expected. Suppose that John, an employee of a department store, is standing fifty meters away from the store in a parking lot. He has a few hundred shopping carts, which he is supposed to push to the store. Since these are too many carts to push all at once, he goes back and forth between the parking lot and the store, and each time he takes a few carts with him. After fifty minutes, his shift is over and he goes home. In this situation, (11a) is true (on an iterative interpretation of its verb phrase), but (11b) is not, even though the distance he travels each time is fifty meters.

(11) a. John pushed carts all the way to the store for fifty minutes.

temporally atelic

b. John pushed carts all the way to the store for fifty meters. 
The difference between (11a) and (11b) can be explained on the assumption that for fifty minutes checks for a property that is parametrized for time, while for fifty meters checks for a property that is parametrized for space. More generally, the contrast between spatial and temporal for-adverbials supports a parametrized notion of the telic-atelic opposition, where the parameter is set either to time or to a spatial dimension.

The predicate John pushed carts all the way to the store may be used to describe a complex sum event like the one that contains everything described in the scenario above. Such an event is depicted in the space-time diagrams in Figure 1, which builds on the spatial metaphor I described above and attempts to convey the intuition behind the explanation I will provide. The left-hand diagram corresponds to (11a) and the right-hand one to (11b).
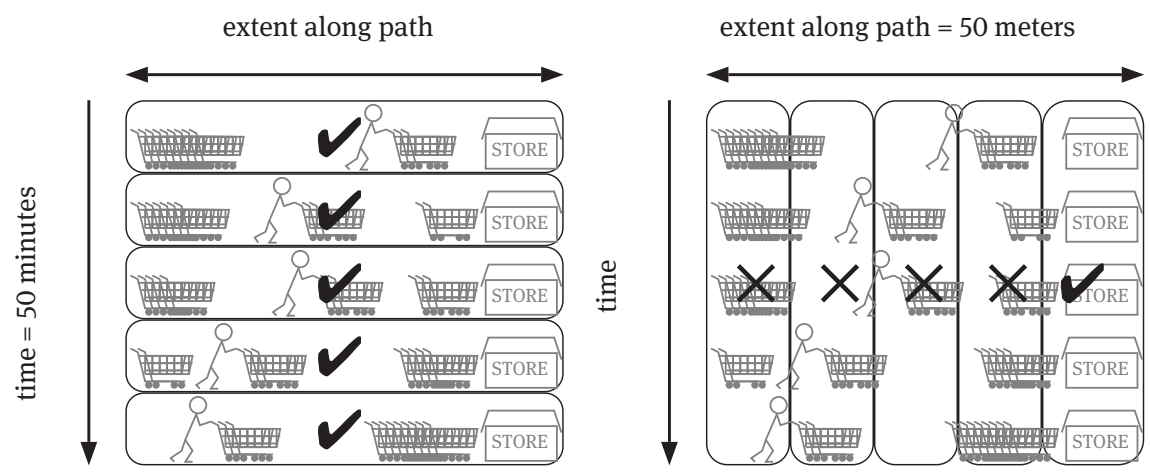

Figure 1: John pushed carts to the store is temporally atelic but spatially telic.

Both sentences require the predicate to hold at very small intervals that are parts of the interval that the for-adverbial introduces. In (11a), this interval is a fiftyminute time span. As long as each subinterval of this time span is the runtime of an event that satisfies the predicate John pushed carts all the way to the store, (11a) is predicted to be acceptable. The events marked with a checkmark in Figure 1 satisfy this predicate in the scenario above. In (11b), the interval is a fifty-meter long path. Most of the subintervals of this path do not contain the location of the store. That (11b) is unacceptable can then be explained by the assumption that an event whose location does not contain the store does not satisfy the predicate John pushed carts all the way to the store. For example, the events marked with an $\mathrm{X}$ on the right-hand diagram of Figure 1 do not satisfy this predicate. Thus, we may say that the iterative interpretation of push carts all the way to the store is atelic with respect to time but not with respect to space. 
The interpretation of predicates as atelic or telic may vary based on a number of factors. For example, a given predicate that is otherwise not compatible with for-adverbials may become compatible with them, and therefore atelic, when it is contextually restricted to events of a certain kind. For example, push carts all the way to the store may become spatially atelic when it is restricted to events that can be subdivided along the relevant spatial dimension (the path to the store). H.-M. Gärtner (p.c.) offers a relevant example of a scenario in which both (11a) and (11b) may be judged acceptable and true. Suppose that the department store is one hundred meters wide, and that along the store's wall there are carts every few meters that are at some distance from the wall. John walks along the store and on a stretch of fifty meters he pushes carts all the way to the wall. In this scenario, (11b) is acceptable and true. If we also suppose that John works at a rate of just one meter per minute, so that he is done after fifty minutes, (11a) is acceptable and true as well. In this paper, I will not formally represent this kind of contextual restriction, since my goal here is to develop a formal notion that adequately captures atelicity, and not to give a comprehensive theory of aspectual composition. For such a theory, see for example Krifka (1998).

According to one influential theory of atelicity, a predicate is atelic-and can combine with for-adverbials-just in case it has the subinterval property (Bennett and Partee 1972; Dowty 1979: 334). This property holds of any predicate $P$ such that whenever $P$ holds at an interval $t$, it also holds at every subinterval of $t$, all the way down to instants. Figuratively speaking, the subinterval property requires that any event in the denotation of a predicate that has this property can be divided into infinitely thin "temporal layers" that are also in the denotation of this atelic predicate. For example, on this view, the predicate walk is atelic because we can "zoom in" to any part of the runtime of a walking event to find a part of it which is another walking event. These shorter walking events are plausibly considered parts, or subevents, of the longer walking events. In the following, I use $\tau$ for the function that maps events to the temporal intervals at which they occur. This function is variously called runtime or temporal trace. These runtimes are time spans located on the historical time axis. I assume that these time spans in turn have durations. An event today and another equally long one tomorrow have distinct runtimes but the same duration. I use $\leq$ both for the parthood (inclusion) relation between intervals and for the parthood relation between events and other entities.

$\forall e\left[\operatorname{walk}(e) \rightarrow \forall t\left[t \leq \tau(e) \rightarrow \exists e^{\prime}\left[\operatorname{walk}\left(e^{\prime}\right) \wedge e^{\prime} \leq e \wedge t=\tau\left(e^{\prime}\right)\right]\right]\right]$

(Whenever walk holds of an event $e$, then at every subinterval of the runtime of $e$, there is a subevent of which walk also holds.) 
The subinterval property has several deficiencies. For one thing, it hard-codes the role of time in the definition of aspect, and must therefore be generalized before it can be used for spatial for-adverbials. Another deficiency is the well-known "minimal-parts problem". The subinterval property requires a predicate to be true at all subintervals, even infinitely short ones. Not all atelic predicates satisfy this stringent criterion. It is sufficient for the predicate to be true at length intervals that count as very small relative to the length of the bigger interval. To mention a classical example, given that any waltzing event takes at least three steps to unfold, example (13a) does not entail that John and Mary waltzed within every single moment of the hour, only that the hour can be divided into very short subintervals such that they waltzed at each of them (Taylor 1977; Dowty 1979: 171). The same observation, mutatis mutandis, can be made for cases that involve spatial for-adverbials, such as example (13b). Here, it is the spatial interval in question which is required to consist of very small parts such that each of which is the spatial extent of a waltzing event.

(13) a. John and Mary waltzed for an hour.

b. John and Mary waltzed for a couple of meters.

The minimal length in question is not fixed once and for all, as shown by the following attested examples:

(14) The Chinese people have created abundant folk arts, such as paper-cuttings, acrobatics, etc., passed on from generation to generation for thousands of years. ${ }^{1}$

(15) Ded'leg says: How i [sic] stop a macro for 1 sec? Cog says: By creating a script that will loop for 3,600 [sic] milliseconds ... ${ }^{2}$

The verb phrases in these examples are clearly atelic since they can be modified by a for-adverbial. The minimal duration of an event in the denotation of pass on from generation to generation is much longer than that of an event denoted by loop. This mirrors the relation between thousands of years and 3,600 milliseconds. This suggests that the minimal-length requirements imposed by for-adverbials are relative to the measure phrases they contain.

While it has long been accepted that the subinterval property is an idealization and that it must be relaxed to account for such examples, there is no consensus on the best way to do so. For reviews of various proposals, see for example Krifka

1 Attested example (http://www.twinbridge.com/detail.aspx?ID=315).

2 Attested example (http://web.archive.org/web/20120429171708/http://www.wowmacroswarcraft. $\mathrm{com} / \mathrm{faq} /$ ). 
(1986: Ch. 2) and Mollá-Aliod (1997: Ch. 4). Here I will develop one particular approach. I defend it against alternatives in Champollion (2010, to appear (b): Chs. 5 and 6). Here is a brief sketch of the problems that some of these alternative approaches face. Hinrichs (1985: 235) proposes that (13a) requires every proper subinterval of the hour to be a subinterval of the runtime of some waltzing event which is a proper part of the hour-long waltzing event in question. As the length of these proper subintervals approaches one hour, the proper parts encompass more and more of the whole event, which has various undesirable consequences. Moltmann (1991) argues for a departure from classical extensional mereology and proposes that (13a) requires John and Mary to waltz at every "relevant or contextually determined" part of the hour in question, but does not say much about what relevant parts are and does not present a formal model. Krifka (1986, 1989, 1992, 1998) and Kratzer (2007) characterize for-adverbials in terms of variations of the notion of divisive reference, which holds of a predicate $P$ if every part of any event in $\mathrm{P}$ is also in P. In other words, the parthood relation between temporal intervals is replaced by a parthood relation between events. Their approach does not make explicit reference to time or space and cannot be easily extended to do so, which makes it difficult to distinguish between temporal and spatial atelicity.

In the metaphor I have developed, we can diagnose the problem with the subinterval property as follows. The subinterval property requires that any event that satisfies a property $\mathrm{P}$ can be cut along the temporal dimension into infinitely thin "layers" each of which satisfies P. While for-adverbials do seem to constrain the event layers to be very thin, they do not have to be infinitely thin. I will call these very thin layers strata and I will amend the subinterval property in a way that will lead to stratified reference. I have chosen the names strata and stratified reference to remind the reader of geological strata, the layers of rock which can be observed in geological formations in places such as the Grand Canyon. A geological stratum can be just a few inches thick, though not infinitely thin, and yet extend over hundreds of thousands of square miles. This aspect is mirrored in the present theory, where strata are constrained to be very thin along one dimension, but may be arbitrarily large as measured in any other dimension. This feature of the theory not only helps capture the distinction between temporal and spatial measure adverbials. It will also become important later, when I will use stratified reference to model different properties at the same time (e.g. atelicity and distributivity) that may not always hold of the same predicates. I will assume that individual constructions set the dimension parameter in different ways when they impose constraints on their constituents. For example, temporal for-adverbials require stratified reference along the temporal dimension only. As far as they are concerned, while the parts of relevant events must be short, or thin, in the temporal dimension, they may still have plural entities as agents or themes, they may be extended in space, and so on. 
The subinterval property says that an atelic predicate distributes along the time dimension down to intervals of infinitely short length. This has turned out to be too strong. Instead, as we have seen, atelic predicates distribute along a certain dimension (which may be either temporal or spatial) down to intervals of a certain length or granularity. To model this, I will add a dimension parameter and a granularity parameter to the subinterval property. I will use the dimension parameter to specify the spatial or temporal dimension, and I will set the granularity parameter to a small but nonzero value in order to maintain the spirit of the subinterval property while avoiding the minimal-parts problem. In my formalization, I will make use of the star operator known from the literature on plural semantics (Link 1983). This operator is defined as follows. I use $\oplus \mathrm{C}$ to refer to the mereological sum of the elements of the set $C$. I assume classical extensional mereology, which means among other things that every nonempty set of entities has a unique sum. For a general introduction to mereology in formal semantics, see Champollion and Krifka (to appear).

\section{(16) Definition of the star operator}

For any nonempty set of entities $P$, let $* P \stackrel{\text { def }}{=}\{A \mid \exists C[A=\oplus C \wedge C \subseteq P]\}$

(A is the sum of all the elements of a subset $C$ of $P$.)

Intuitively, $x \in{ }^{*} P$ means that $x$ consists of one or more parts such that $P$ holds of every one of these parts. To put it differently, if $x \in{ }^{*} P$ then either $P$ holds of $x$ itself, or there is a way to divide $x$ into parts that form a subset of $P$. I will switch freely between predicate-argument notation, set membership notation, and lambda abstraction notation. Thus, the following three statements are equivalent: (i) ${ }^{*} P(x)$; (ii) $x \in{ }^{*} P$; and (iii) $x \in{ }^{*} \lambda y \cdot P(y)$.

I will use the following conventions for basic types: $t$ for propositions, $e$ for ordinary objects, $v$ for events, $i$ for intervals, $d$ for degrees (of height, weight, volume, speed, etc.), and $n$ for numbers. I use the symbols $x, y, z, x^{\prime}, y^{\prime}, z^{\prime}$ and so on for variables that range over ordinary objects, $e, e^{\prime}, e^{\prime \prime}$ for events, $t, t^{\prime}, t^{\prime \prime}$ for temporal intervals, $l, l^{\prime}, l^{\prime \prime}$ for spatial extents (locations), $d$ for degrees and $n, n^{\prime}$, $n^{\prime \prime}$ for numbers. Sometimes I will use variables that can range over entities of different types. I will write $\alpha$ to range over any basic type.

In order to model different levels of granularity, I will assume that there is a vague predicate $\varepsilon$ that takes a set $K$ of type $\langle\alpha, t\rangle$ and an entity $x$ of type $\beta$, where $\alpha$ and $\beta$ range over at least the following basic types: temporal intervals, spatial extents, degrees, and numbers. I assume that $\varepsilon(K)(x)$ holds just in case $x$ counts as very small as compared to the comparison class K. For example, $\varepsilon(\lambda t[\operatorname{hours}(t)=1])\left(t^{\prime}\right)$ is true just in case $t^{\prime}$ is very small with respect to the set of all temporal intervals whose length is) one hour. For now, I will assume that $\varepsilon$ 
is only defined if $\alpha=\beta$, since it will generally not be necessary to compare across basic types. In Section 4, we will have occasion to relax this requirement. Using the $\varepsilon$ predicate, we can formally express what it means for the predicate waltz to have the property we have discussed above:

$$
\forall e\left[\operatorname{waltz}(e) \rightarrow e \in^{*} \lambda e^{\prime}\left(\begin{array}{l}
\operatorname{waltz}\left(e^{\prime}\right) \wedge \\
\varepsilon(\lambda t[\operatorname{hours}(t)=1])\left(\tau\left(e^{\prime}\right)\right)
\end{array}\right)\right]
$$

This formula can be paraphrased as follows:

(18) Every waltzing event can be divided into one or more parts, each of which is a waltzing event whose runtime is very short compared with one hour.

I will use the formulation "can be divided into one or more parts" frequently. An equivalent formulation that is perhaps easier to understand, but that does not match the structure of the formula as closely, is the following:

(19) Every waltzing event whose runtime is not very short compared with one hour can be divided into waltzing events whose runtime are very short compared with one hour.

Let us say that waltz has stratified reference with respect to the dimension runtime and the granularity $\varepsilon(\lambda t$ [hours $(t)=1]$ ) (which is true of any interval very short as compared to an hour), formally: $\operatorname{SR}_{\tau, \varepsilon(\lambda t[\operatorname{hours}(t)=1])}(\lambda e$.waltz $(e))$, just in case (17) is true. By abstracting from this example, we arrive at the following definition:

(20) Stratified reference (Definition)

$$
\left.\operatorname{SR}_{f, \varepsilon(K)}(P) \stackrel{\text { def }}{=} \forall x\left[P(x) \rightarrow x \in \in^{*} \lambda y \begin{array}{ll}
P(y) \wedge \\
& \varepsilon(K)(f(y))
\end{array}\right)\right]
$$

This definition says that stratified reference applies to a predicate $P$ just in case the following is true: whenever $P$ holds of an entity or event $x$, there is a way to divide $x$ into strata $y_{1}, y_{2}$, etc. such that each $y_{i}$ is mapped by the function $f$ to a value which counts as very small with respect to the comparison class $K$. This is illustrated in Figure 2, where the vertical axis represents the dimension $f$. In case $f$ is instantiated with runtime, stratified reference approximately amounts to the subinterval property, except that the minimal-parts problem is avoided.

I propose that being temporally atelic means having stratified reference with respect to time and a suitably instantiated granularity parameter. For-adverbials require stratified reference, not the subinterval property. For concreteness, I will 


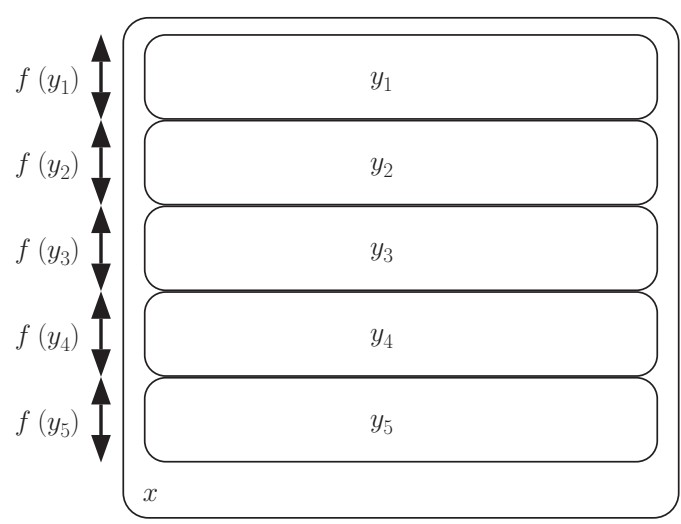

Figure 2: Stratified reference.

assume that this requirement is a presupposition and I will represent it as a definedness requirement, but nothing hinges on these assumptions. (It could also be seen as a kind of selectional restriction, for example.) I write $\lambda x: \varphi \cdot \psi$ for the partial function that is defined for all $x$ such that $\varphi$ holds, and that returns $\psi$ wherever the function is defined (Heim and Kratzer 1998: Ch. 4). My entry for for is as follows:

$$
\text { (21) } \llbracket \text { for } \rrbracket=\lambda \tau_{\langle v i\rangle} \lambda M_{\langle i t\rangle} \lambda P_{\langle v t\rangle} \lambda e: \mathrm{SR}_{\tau, \varepsilon(M)}(P) . P(e) \wedge M(\tau(e))
$$

This entry combines with a temporal or spatial trace function $\tau$ (depending on whether the for-adverbial is temporal or spatial), which we may assume is provided by a silent head. It then combines with a measure phrase $M$ (such as an hour, which I assume denotes a set of temporal intervals) and a verb phrase P (such as waltz, a set of events) and presupposes that $\mathrm{P}$ has stratified reference with respect to the two specified parameters, in this case dimension $\tau$ (runtime) and granularity $\varepsilon(\lambda t$.hours $(t)=1)$. This presupposition tolerates the possibility that very short waltzing events are not infinitely divisible into even shorter ones, and is therefore satisfied even though waltz may not have the subinterval property. This is summarized in (22). I will provide similar summaries throughout the rest of this paper.

(22) waltz for an hour

Satisfied presupposition: $\mathrm{SR}_{\tau, \varepsilon(\lambda t[\operatorname{hours}(t)=1])}(\lambda e \cdot \operatorname{waltz}(e))$, that is:

$$
\forall e\left[\operatorname{waltz}(e) \rightarrow e \in{ }^{*} \lambda e^{\prime}\left(\begin{array}{l}
\operatorname{waltz}\left(e^{\prime}\right) \wedge \\
\varepsilon(\lambda t[\operatorname{hours}(t)=1])\left(\tau\left(e^{\prime}\right)\right)
\end{array}\right)\right]
$$

(Every waltzing event can be divided into one or more parts, each of which is a waltzing event whose runtime is very short compared with one hour.) 
By assuming that different for-adverbials set the granularity parameter of the stratified reference conditions that they impose to different values, we can model the fact that atelicity is a relative notion, as seen in examples (14) and (15). The analyses of these examples are as follows:

(23) pass on from generation to generation for thousands of years

\section{Satisfied presupposition:}

$\mathrm{SR}_{\tau, \varepsilon(\lambda t[\text { thousands }(\operatorname{years}(t))])}(\lambda e$.pass.on.from.generation.to.generation $(e)) \Leftrightarrow$ $\forall e[$ pass.on.from.generation.to.generation $(e) \rightarrow$

$\left.e \in{ }^{*} \lambda e^{\prime}\left(\begin{array}{l}\text { pass.on.from.generation.to.generation }\left(e^{\prime}\right) \wedge \\ \varepsilon(\lambda t[\text { thousands }(\text { years }(t))])\left(\tau\left(e^{\prime}\right)\right)\end{array}\right)\right]$

(Every event that can be described as pass on from generation to generation can be divided into one or more parts, each of which can be described as pass on from generation to generation and has a runtime that is very short compared with thousands of years.)

(24) loop for 3,600 milliseconds

Satisfied presupposition: $\operatorname{SR}_{\tau, \varepsilon(\lambda t[\operatorname{milliseconds}(t)=3600])}(\lambda e . \operatorname{loop}(e)) \Leftrightarrow$ $\forall e\left[\operatorname{loop}(e) \rightarrow e \in \epsilon^{*} \lambda e^{\prime}\left(\begin{array}{l}\operatorname{loop}\left(e^{\prime}\right) \wedge \\ \varepsilon(\lambda t[\operatorname{milliseconds}(t)=3600])\left(\tau\left(e^{\prime}\right)\right)\end{array}\right)\right]$

(Every looping event can be divided into one or more parts, each of which is a looping event whose runtime is very short compared with 3,600 milliseconds.)

Again, these presuppositions are plausibly satisfied. Even though at least example (23) does not involve a property that has the subinterval property, it passes muster because the granularity parameter is set to a very coarse level.

Finally, stratified reference can also be used to model spatial aspect. Examples like (8a) (The road meanders for a mile) do not require the road in question to meander throughout its entire length, just like the sentence John walked for an hour does not require John to walk throughout his entire lifetime. To represent this fact, I assume that the relevant sentences involve underlying states and that these states may be spatiotemporally extended, just like events (Parsons 1987). The state that verifies The road meanders will have the same spatial extent as the meandering part of the road. These states play the same role in the compositional process as events, so I represent them with the same variable $e$. I assume that a state is mapped to its spatial extent by a function I will write as $\sigma$ (Zwarts 2006). Given this, we can translate a spatial for-adverbial as in (25). This translation imposes a stratified reference requirement that is 
parametrized for $\sigma$ (spatial extent) instead of $\tau$ (time) and is otherwise equivalent to my translation of the temporal for-adverbial. Other spatial measure adverbials, such as worldwide and throughout the country in (10), can be represented in similar ways.

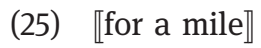

$=\lambda P_{\langle v t\rangle} \lambda e: \operatorname{SR}_{\sigma, \varepsilon(\lambda[\operatorname{miles}(l)=1])}(P) . P(e) \wedge \operatorname{miles}(\sigma(e))=1$

With this in place, we can easily capture the requirement of spatial for-adverbials and related expressions, as the following examples show:

(26) meander for a mile

Satisfied presupposition: $\operatorname{SR}_{\sigma, \varepsilon(\lambda[\operatorname{miles}(l)=1])}(\lambda e \cdot$ meander $(e)) \Leftrightarrow$

$\forall e\left[\operatorname{meander}(e) \rightarrow e \in *^{*} \lambda e^{\prime}\left(\begin{array}{l}\operatorname{meander}\left(e^{\prime}\right) \wedge \\ \varepsilon(\lambda l[\operatorname{miles}(l)=1])\left(\sigma\left(e^{\prime}\right)\right)\end{array}\right)\right]$

(Every meandering state can be divided into one or more parts, each of which is a meandering state whose spatial extent is very small compared with one mile.)

(27) cause protests throughout the country

Satisfied presupposition:

$\operatorname{SR}_{\sigma, \varepsilon(\lambda[l[=\sigma(\text { the.country })])}\left(\right.$ cause $(e) \wedge{ }^{*} \operatorname{protest}($ theme $(e)) \Leftrightarrow$

$\forall e\left[\operatorname{cause}(e) \wedge^{*} \operatorname{protest}(\operatorname{theme}(e)) \rightarrow\right.$

$\left.e \in^{*} \lambda e^{\prime}\left(\begin{array}{l}\operatorname{cause}\left(e^{\prime}\right) \wedge^{*} \operatorname{protest}\left(\operatorname{theme}\left(e^{\prime}\right)\right) \wedge \\ \varepsilon(\lambda l[l=\sigma(\text { the.country })])\left(\sigma\left(e^{\prime}\right)\right)\end{array}\right)\right]$

(Every state of causing protests can be divided into one or more parts, each of which is a state of causing protests whose spatial extent is very small compared with the spatial extent of the country.)

To summarize this section, for-adverbials and related constructions are sensitive to the temporal/spatial opposition and to different granularities in ways that motivate an appropriate generalization of the subinterval property. This generalization, stratified reference, builds on the basic intuition behind algebraic semantic accounts of aspect - namely, that atelicity can be defined in terms of a predicate applying to the parts of an event in question - but generalizes it by adding parameters that allow us to explicitly model varying dimensions and granularities. 


\section{Measurement}

Now that we have seen how stratified reference characterizes the telic-atelic opposition and allows us to avoid the minimal-parts problem and generalize to spatial aspect, let us turn to measurement in natural language. Several measurement-related constructions turn out to be sensitive to a number of oppositions that can all be characterized using stratified reference. Aside from measure adverbials like for an hour, I will focus on pseudopartitives (Selkirk 1977). As the following examples illustrate, pseudopartitives can be used to talk about substances and events in terms of their measurement along various dimensions (Krifka 1998; Schwarzschild 2006):

(28) a. five pounds of rice

weight

b. five liters of water volume

c. five hours of talks temporal trace

d. five miles of railroad tracks

spatial extent

There are two semantic parallels between pseudopartitives and for-adverbials. First, both reject predicates that fail to apply to the parts of the entities and events in their denotation. This category includes telic predicates in the case of for-adverbials, as we have seen in the previous section, and count nouns in the case of pseudopartitives, as illustrated in (29). It is not possible to use a pseudopartitive like the one in (29c) to describe a single book whose weight is five pounds.

(29) a. five pounds of books

b. five pounds of rice

c. *five pounds of book (unacceptable with "book" as a count noun)

There are several irrelevant interpretations that may be available for (29c) when the identity of the books in question is not at issue or not recoverable. For example, it may be interpreted as describing five pounds of books in a situation where the books are sold by weight, or five pounds of pulp that result from shredding books. In such cases I assume the count noun book has been coerced to a mass noun. I leave these interpretations aside since they correspond to (29b), where a mass noun is used.

The second semantic parallel between pseudopartitives and for-adverbials is that both of them reject measure functions whose value tends to stay constant across the parts of any object or event they measure. I will first illustrate this phenomenon with pseudopartitives and come back to for-adverbials later. 
Examples of such functions are speed, as illustrated by examples (30a) and (30b), and temperature, as in example (30c).

(30) a. *run (to the store) for five miles an hour

b. five hours of running $v s$. *five miles an hour of running

c. five inches of water vs. ${ }^{\star}$ five degrees (Celsius) of water

Although I will focus on pseudopartitives and for-adverbials in this section, several other constructions behave analogously. For example, when comparative determiners are used with substance mass nouns, they are underspecified as to what measure function is involved (Schwarzschild 2006). Thus, more rope can mean "a longer portion of rope" or "a heavier portion of rope" in different contexts, depending on what is relevant. It is not possible, however, to use comparative determiners to compare two amounts of rope by temperature. In other words, it is not possible to come up with a context in which more rope can be used felicitously to mean "a warmer portion of rope". True partitives are another construction that behaves similarly to pseudopartitives in terms of rejecting certain measure functions, as shown here:

(31) a. *five degrees Celsius of the water in this bottle

b. ${ }^{\star}$ five miles per hour of my driving

${ }^{*}$ temperature

*speed

From the examples so far, one might think that certain measure functions are never acceptable in pseudopartitives. But in fact, measure functions that are usually unacceptable can be made acceptable when the substance noun is chosen in the right way, as in the following attested example:

(32) The scientists from Princeton and Harvard universities say just two degrees Celsius of global warming, which is widely expected to occur in coming decades, could be enough to inundate the planet. ${ }^{3}$

Thus, we cannot simply categorize measure functions as acceptable or unacceptable per se. What matters is whether they are acceptable on the set denoted by the substance noun of the pseudopartitive in which they appear.

The fact that pseudopartitives accept certain measure functions but reject others has previously been linked to the measure-theoretic properties of these measure functions. As discussed by Krifka (1998) and Schwarzschild (2006), the

3 Attested example (Calgary Herald, December 17, 2009, article: Two degrees is all it takesWarming may trigger floods). 
constraint corresponds to a distinction commonly made in measurement theory and in physics, namely the one between extensive and intensive measure functions. In physics, an extensive measure function is one whose magnitude is additive for subsystems; an intensive measure function is one whose magnitude is independent of the extent of the system (Krantz et al. 1971; Mills et al. 2007). For example, when one considers the system consisting of the water in a tank, volume is an extensive measure function because it is additive, meaning that the volume of the water as a whole is greater than the volume of any of its proper parts. But temperature is intensive with respect to this system because the temperature of the water as a whole is no different from the temperature of its proper parts. Krifka (1998) suggests that only extensive measure functions are admissible in pseudopartitives.

A related notion to extensive measure functions is that of a monotonic measure function. A function $\mu$ is monotonic iff for any two entities $a$ and $b$ in the physical world, if $a$ is a proper part of $b$, then $\mu(a)$ is less than $\mu(b)$. Schwarzschild (2006) suggests that only monotonic measure functions are admissible in pseudopartitives. For example, volume is monotonic, so we have an explanation of why thirty liters of water is acceptable. Temperature is not monotonic, which explains why ${ }^{*}$ thirty degrees Celsius of water is not acceptable.

Krifka's and Schwarzschild's accounts are attractive, and my theory will subsume their core idea, but they undergenerate in certain cases like the following:

\section{(33) Five feet of snow fell on Berlin.}

Although (33) is acceptable, height is not monotonic. For example, imagine that five feet of snow fell on Berlin. The snow that fell on West Berlin is a proper part of the snow that fell on Berlin. But if height was monotonic, we would conclude that the height of the snow in West Berlin is less than five feet, contrary to fact.

Schwarzschild (2006: 75) is aware of the problem. From similar examples, he concludes that pseudopartitives do not test for monotonicity with respect to the mereological part-whole relation, but only with respect to a part-whole relation which he sees as contextually supplied. In our example, his assumption would be that context provides a relation according to which the snow that fell on West Berlin is not a part of the snow that fell on the entire city. Schwarzschild does not impose any formal constraints on the contextually supplied part-whole relation he assumes. However, since many measure functions like temperature are already correctly ruled out even without replacing the mereological partwhole relation by a contextually supplied relation, the two relations must coincide to a large extent, which suggests a certain redundancy. 
To draw on the intuition behind Krifka's and Schwarzschild's account without making this appeal to context necessary, I will relativize monotonicity to a certain dimension, such as height in the snow example. Furthermore, to account for the effect that the choice of substance noun matters, I will relativize it to the property denoted by the substance noun. I will do this by using stratified reference, which applies to a given property, and which can be parametrized for a given dimension. In the previous section, I used the difference between temporal and spatial for-adverbials as motivation for the dimension parameter.

Schwarzschild suggests that the telic-atelic opposition can be formalized in terms of monotonicity. For example, in-adverbials can only combine with telic predicates because, as he puts it, runtime "is nonmonotonic on the relevant part-whole relation in the domain given by" that predicate. For him, runtime is a dimension that is monotonic on the part-whole relation that relates events to their subevents. So Schwarzschild uses monotonicity to subsume what I have captured through stratified reference. I propose to go in the opposite direction and use stratified reference to subsume what Schwarzschild captures through monotonicity.

Using stratified reference for both measure adverbials and pseudopartitives predicts a link between the two domains. This prediction is borne out by the following observation (Champollion 2010: Ch. 7). Those measure functions that are rejected by pseudopartitives are also rejected by for-adverbials:

(34) a. John waited for five hours.

b. The crack widens for five meters.

c. *John drove for thirty miles an hour.

d. *The soup boiled for 100 degrees Celsius.

temporal trace spatial extent

*speed

*temperature

The following modifications of examples (34c) and (34d) show that these examples cannot be ruled out on the grounds that events are not the kinds of things that have speeds and temperatures.

(35) a. John drove (at) thirty miles an hour.

speed

b. The soup boiled at 100 degrees Celsius.

temperature

So it is really something about for-adverbials, and not just about verbal modification in general, that rules out intensive measure functions like speed and temperature.

Just as we did in the case of pseudopartitives, we can identify properties which make it possible to use measure functions that are otherwise incompatible 
with for-adverbials. The following attested example shows this for the case of temperature:

(36) The sample continued to cool for several degrees to point $\mathrm{N}$ and then suddenly increased to a temperature between the transition points of Form I and Form II with no indication of the presence of Form III. ${ }^{4}$

These facts about for-adverbials provide further justification for the decision to link the domains of aspect and measurement via stratified reference. On the assumption that pseudopartitives give rise to the same kinds of parametrized presuppositions as temporal and spatial for-adverbials do, the relevant examples can be ruled out because the presuppositions that stratified reference generates for them can plausibly be assumed to fail:

(37) *drive for 30 miles per hour

Failed presupposition: $\operatorname{SR}_{\text {speed }, \varepsilon(\lambda d[\operatorname{mph}(d)=30])}(\lambda e$.drive $(e)) \Leftrightarrow$ $\forall e\left[\operatorname{drive}(e) \rightarrow e \in \epsilon^{*} \lambda e^{\prime}\left(\begin{array}{l}\operatorname{drive}\left(e^{\prime}\right) \wedge \\ \varepsilon(\lambda d[\operatorname{mph}(d)=30])\left(\operatorname{speed}\left(e^{\prime}\right)\right)\end{array}\right)\right]$

(Every driving event can be divided into one or more parts, each of which is a driving event whose speed is very slow compared with thirty miles per hour.)

(38) *boil for 100 degrees Celsius

Failed presupposition: $\operatorname{SR}_{\text {temperature }, \varepsilon(\lambda d[\operatorname{Celsius}(d)=100])}(\lambda e \cdot \operatorname{boil}(e)) \Leftrightarrow$ $\forall e\left[\operatorname{boil}(e) \rightarrow e \in e^{*} \lambda e^{\prime}\left(\begin{array}{l}\operatorname{boil}\left(e^{\prime}\right) \wedge \\ \varepsilon(\lambda d[\operatorname{Celsius}(d)=100])\left(\operatorname{temperature}\left(e^{\prime}\right)\right)\end{array}\right)\right]$

(Every boiling event can be divided into one or more parts, each of which is a boiling event whose temperature is very low compared with 100 degrees Celsius.)

These presuppositions fail because the subevents of a driving event typically have the same speed as that event, and similarly for the subevents of boiling events and their temperatures.

Since stratified reference is presupposed to hold of verb phrases, it is not surprising that specific verb phrases can rescue constructions that would otherwise be unacceptable, as in the case of temperature-based for-adverbials. For the following example, which is modeled on (36), I assume that the relevant measure function, which I write temperature-drop, maps any cooling event to the number of degrees that it causes the temperature to drop.

4 Attested example, from Daubert and Clarke (1944). 
(39) cool for five degrees

Satisfied presupposition: $\operatorname{SR}_{\text {temperature-drop }, \varepsilon(\lambda d[\operatorname{Celsius}(d)=5])}(\lambda e \cdot \operatorname{cool}(e)) \Leftrightarrow$ $\forall e\left[\operatorname{cool}(e) \rightarrow e \in e^{*} \lambda e^{\prime}\left(\begin{array}{l}\operatorname{cool}\left(e^{\prime}\right) \wedge \\ \varepsilon(\lambda d[\text { Celsius }(d)=5])\left(\text { temperature-drop }\left(e^{\prime}\right)\right)\end{array}\right)\right]$

(Every cooling event can be divided into one or more parts, each of which is a cooling event that involves a temperature drop whose extent is very small compared with five degrees Celsius.)

On the plausible assumption that every cooling process causes the temperature of the affected entity to drop continuously, this presupposition is satisfied.

It seems reasonable to assume that the same presupposition that is found in for-adverbials is also found in pseudopartitives. The intuition here is that a for-adverbial construction like run for three hours has essentially the same semantics as the corresponding pseudopartitive construction three hours of running, and that it gives rise to the same presupposition. In substancedenoting pseudopartitives, I assume that the dimension parameter is set to the appropriate measure function. For example, in thirty liters of water, this measure function is volume, and the resulting presupposition is plausibly satisfied:

(40) thirty liters of water

Satisfied presupposition: $\operatorname{SR}_{\text {volume }, \varepsilon(\lambda d[\operatorname{liters}(d)=30])}(\lambda x$.water $(x)) \Leftrightarrow$ $\forall x\left[\operatorname{water}(x) \rightarrow x \in *^{*} \lambda y\left(\begin{array}{l}\text { water }(y) \wedge \\ \varepsilon(\lambda d[\operatorname{liters}(d)=30])(\operatorname{volume}(y))\end{array}\right)\right]$

(Every amount of water can be divided into one or more parts, each of which is an amount of water whose volume is very small compared with thirty liters.)

Mass nouns like water (as we have just seen) and plural count nouns like books are acceptable on the plausible assumption that they have approximate divisive reference (Link 1983; Krifka 1998): Whenever they apply to an entity, they also apply to all of its parts (leaving aside very small parts). By contrast, singular count nouns are ruled out on the assumption that they are quantized (that is, they do not apply to any proper parts of any entity to which they apply), as proposed by Krifka (1998). This is shown in the following example:

(41) * five pounds of book

Failed presupposition: $\operatorname{SR}_{\text {weight }, \varepsilon(\lambda d[\operatorname{pounds}(d)=5])}(\lambda x \cdot \operatorname{book}(x)) \Leftrightarrow$

$\forall x\left[\operatorname{book}(x) \rightarrow x \in *^{*} \lambda y\left(\begin{array}{l}\operatorname{book}(y) \wedge \\ \varepsilon(\lambda d[\operatorname{pounds}(d)=5])(\operatorname{weight}(y))\end{array}\right)\right]$

(Every book can be divided into one or more parts, each of which is a book whose weight is very small compared with five pounds.) 
The presupposition in (41) fails for two reasons: (i) typically, a book's weight is not very small compared with five pounds, so we cannot read the "one or more parts" as "one part"; (ii) a book does not consist of proper parts which are themselves books, so we cannot read the "one or more parts" as "two or more parts". The assumption that singular count nouns are quantized rules out the possibility that a book has any parts besides itself, and therefore a fortiori it is not possible for any part of a book to be very small in weight compared with the weight of the book itself. (In many cases we could even use the weaker assumption that it may be that a book does have mereological parts-its spine, for example-but that in that case none of these parts qualifies as a book.)

Expressions such as (42) are ruled out as well if book is interpreted as a count noun, though they are ruled out for a different reason than (41) is.

\section{*five tons of book}

Let us assume (plausibly) that every book's weight is very small compared with five tons. Therefore it will always be possible to divide every book into one or more parts (namely into one part) whose weight is very small compared with five tons. So reason (i) is now no longer relevant, and the presupposition of this expression is actually satisfied. The reason (42) is ruled out is its at-issue meaning. Following Schwarzschild (2006) and others, I assume that pseudopartitives are interpreted intersectively. This means that (42) denotes the intersection of the set of books with the set of objects whose weight is five tons. But this intersection is empty, because by assumption no book weighs five tons. Hence (42) does not hold of any object and this explains its deviance.

Turning to the problematic example of the snow that fell on Berlin, it can be given an account as follows:

(43) five feet of snow

Satisfied presupposition: $\mathrm{SR}_{\text {height }, \varepsilon(\lambda d[\text { feet }(d)=5])}(\lambda x \cdot \operatorname{snow}(x)) \Leftrightarrow$

$\forall x\left[\operatorname{snow}(x) \rightarrow x \in *^{*} \lambda y\left(\begin{array}{l}\operatorname{snow}(y) \wedge \\ \varepsilon(\lambda d[\operatorname{feet}(d)=5])(\operatorname{height}(y))\end{array}\right)\right]$

(Every amount of snow can be divided into one or more parts (horizontal layers), each of which is an amount of snow whose height is very small compared with five feet.)

This presupposition is satisfied in the Berlin scenario because horizontal layers of snow can play the role of the parts. The presupposition does not require height to be monotonic, so the example is acceptable in spite of the fact that the snow on West Berlin and the snow on East Berlin have the same height as the snow that fell on Berlin as a whole. 
The idea behind this account can again be understood via the visual metaphor introduced in Section 1. A plural or mass entity to which a pseudopartitive applies is divided into strata which are very small as measured in the dimension determined by the pseudopartitive, but may extend arbitrarily in other dimensions. These strata are then required to be in the denotation of the noun. Singular count nouns always fail this test because the individuals in their denotation are atomic, and cannot be further subdivided into strata. Figure 3 illustrates what (43) expresses formally: The measure function height is acceptable in the pseudopartitive five feet of snow because every amount of snow can be divided into parts (horizontal layers) of snow whose height is very small compared to five feet.

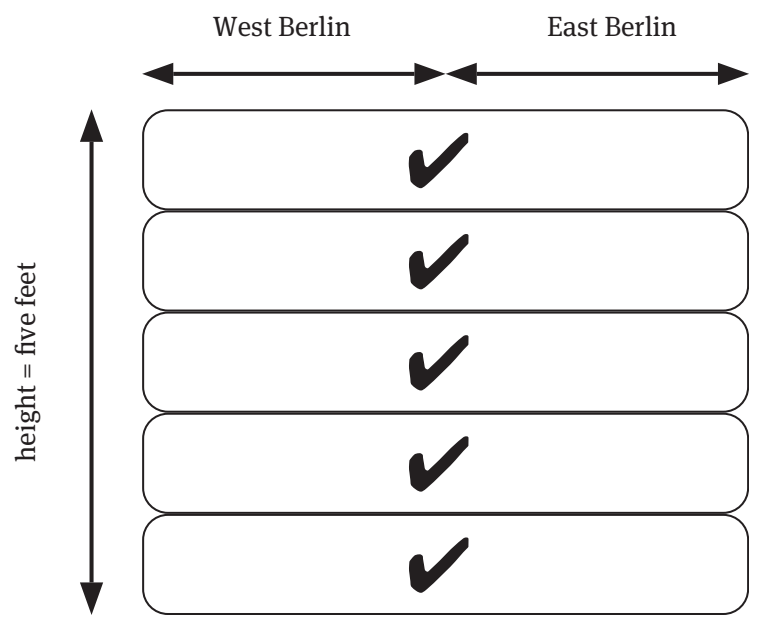

Figure 3: Accepting five feet of snow.

Like previous accounts, we still rule out examples involving temperature and similar intensive measure functions:

(44) *thirty degrees Celsius of water

Failed presupposition: $\mathrm{SR}_{\text {temperature }, \varepsilon(\lambda d[\operatorname{Celsius}(d)=5])}(\lambda X$.water $(x)) \Leftrightarrow$ $\forall x\left[\operatorname{water}(x) \rightarrow x \in *^{*} \lambda y\left(\begin{array}{l}\operatorname{water}(y) \wedge \\ \varepsilon(\lambda d[\operatorname{Celsius}(d)=30])(\operatorname{temperature}(y))\end{array}\right)\right]$

(Every amount of water can be divided into one or more parts, each of which is an amount of water whose temperature is very low compared with thirty degrees Celsius.)

This presupposition fails as desired since the parts of a given amount of water will generally have the same temperature as the entire amount. The constraint 
takes the substance noun into account, so we correctly predict the contrast between unacceptable cases like (30c) (*five degrees (Celsius) of water) and acceptable cases like (32) (two degrees of global warming). I assume that the measure function relevant in (32), which I write temperature-increase, maps any warming event to the number of degrees of warming that it causes.

(45) two degrees Celsius of global warming

\section{Satisfied presupposition:}

$\mathrm{SR}_{\text {temperature-increase }, \varepsilon(\lambda d[\operatorname{Celsius}(d)=2])}(\lambda$ e.global. $\operatorname{warming}(e)) \Leftrightarrow$ $\forall e$ [global.warming $(e) \rightarrow$

$\left.\left.\begin{array}{ll}e \in *^{*} \lambda e^{\prime} & \text { global.warming }\left(e^{\prime}\right) \wedge \\ & \varepsilon(\lambda d[\operatorname{Celsius}(d)=2])\left(\text { temperature-increase }\left(e^{\prime}\right)\right)\end{array}\right)\right]$

(Every amount of global warming can be divided into one or more parts, each of which is an amount of global warming that is very low compared with two degrees Celsius.)

The granularity parameter of stratified reference also makes it natural to account for an observation by Bale (2009): Pseudopartitives that are used to talk about very small quantities accept mass nouns but reject count nouns. A pseudopartitive as a whole cannot be predicated of an entity that is too small to be in the denotation of the substance noun. This is shown by the following examples. As discussed above, I assume that pseudopartitives are incompatible with singular count nouns because these nouns are quantized and this leads to a failure of the stratified reference presupposition. So whenever the word occurs in the singular, it is the mass sense of the word apple (which denotes portions of apple, that is, applesauce or apple slices) which is at play here. As for apples, it denotes the plural of the count noun apple rather than of the mass noun apple, because mass nouns cannot be pluralized. The semantics of plural formation can be represented using the star operator (e.g. Link 1983). This means that portions of apple do not enter the extension of apples because they are not in the denotation of the singular count noun, and because the star operator closes predicates under sum but not under parthood.

(46) a. Give me 500 grams of apple/apples.

b. Give me 100 grams of apple/?apples.

c. Give me one gram of apple/??apples.

The status of examples (46b) and (46c) can be accounted for through the vague predicate $\varepsilon$, on the assumption that the weight of a typical apple qualifies as very small in comparison with 500 grams but not in comparison with one gram, and that 100 grams is a borderline case. 
The difference between mass and count uses of apple is also shown in the following attested example:

(47) Lee said Americans eat the equivalent of one-fifth of a fresh apple each day, or about 19.7 pounds a year. But they should eat five times that much - at least one apple a day, he said. The Cornell researchers found that just 100 grams of apple have the same antioxidant activity as 1,500 milligrams of Vitamin C. (The average apple weighs 150 grams, or about 5 ounces.) ${ }^{5}$

This example becomes worse if the substance noun in 100 grams of apple is replaced by apples. Intuitively, this substitution has the effect that the example is now about whole apples instead of portions of apple. Stratified reference predicts this fact on the assumption that the weight of the smallest apples is not very small compared to 100 grams, let alone compared to one gram. But the weight of applesauce (that is, of stuff that qualifies as apple in the mass sense) can be very small down to milligrams. A similar pattern can be observed in the following squish (Eytan Zweig, p.c):

(48) a. *twelve pounds of twelve-pound weights

b. ?twelve pounds of six-pound weights

c. twelve pounds of four-pound weights

d. twelve pounds of three-pound weights

e. twelve pounds of two-pound weights

f. twelve pounds of one-pound weights

This account predicts that sentences (48a) through (48f) are only acceptable to the extent that the presupposition in (49) is satisfied. Here I write n-poundweights to abbreviate the pluralized predicates denoted by twelve-pound weights, six-pound weights, etc. corresponding to the examples in (48).

(49) twelve pounds of $n$-pound weights

Presupposition: $\mathrm{SR}_{\text {weight }, \varepsilon(\lambda d[\operatorname{pounds}(d)=12])}(\lambda x . n$-pound-weights $(x)) \Leftrightarrow$ $\forall x\left[n\right.$-pound-weights $\left.(x) \rightarrow x \in *^{*} \lambda y\left(\begin{array}{l}n \text {-pound-weights }(y) \wedge \\ \varepsilon(\lambda d[\operatorname{pounds}(d)=12])(\operatorname{weight}(y))\end{array}\right)\right]$

(Every sum of one or more $n$-pound weights can be divided into one or more parts, each of which is a sum of one or more $n$-pound weights whose combined weight is very small compared with twelve pounds.)

5 Attested example (http://www.fowlerfarms.com/apple_a_day.htm). 
In other words, the pseudopartitives in (48) presuppose that every sum consisting of one or more $n$-pound weights consists of $n$-pound weights that weigh much less than twelve pounds. Whether this will turn out to be true, false, or borderline depends on the choice of $n$.

To summarize, we can characterize the class of admissible measure functions as follows: A pseudopartitive has to satisfy stratified reference, where the dimension parameter is specified by the measure function and the granularity parameter is specified based on the measure phrase of the pseudopartitive. The constraint on measure functions is also instantiated in true partitives, comparative determiners, for-adverbials, and other constructions. An event pseudopartitive like three hours of running is given the same analysis as a for-adverbial like run for three hours. This explains why the two constructions also license the same measure functions. The constraint that rules out intensive measure functions like temperature proposed by Krifka (1998) and Schwarzschild (2006) is subsumed by the same constraint that also prevents telic predicates from combining with for-adverbials.

In this section, I have exploited one of the defining features of stratified reference, namely that it pushes us towards thinking of unboundedness as relativized to a certain dimension, thematic role, or measure function. The example five feet of snow has played the same role as the example push carts to the store above. Both examples force us to consider two dimensions at once: height and width in the first case, time and space in the second. The insight from Schwarzschild (2006) that the constraint that comes with five feet of snow must be checked on horizontal layers of snow rather than on every subregion of snow finds a natural explanation in this framework.

\section{Distributivity and collectivity}

The traditional view on for-adverbials and aspect, as we have seen in Section 2, is that the contribution of for an hour can roughly be paraphrased as at each subinterval within an hour and that this is only compatible with atelic predicates. Stratified reference generalizes this view in various ways. The paraphrase contains the word each, which suggests that there may be a connection between atelicity and distributivity. In this section I establish such a connection, and I show that the collective-distributive opposition can be formally related to the telic-atelic opposition. Concretely, I use stratified reference in two ways: first, in order to formulate meaning postulates that capture distributivity, and second, in order to model a distinction within the class of collective predicates.

As is frequently done, I understand "distributivity", and its opposite "collectivity”, as properties of predicates. For example, predicates like smile, see, 
run, breathe and so on are distributive; predicates like be numerous, be a good team, gather, meet, disperse, hold hands and so on are collective. Distributive predicates give rise to what will be called distributive entailments from pluralities to individuals; for example, (50a) entails (50b).

(50) a. John and Mary smiled.

b. John smiled and Mary smiled.

Collective predicates lack these entailments, or give rise to them in a different way. I come back to this point below. For a general introduction to distributivity and collectivity, see also Champollion (to appear(a)).

It has often been suggested that the distributive-collective opposition can be captured by formulating meaning postulates for distributive predicates (e.g. Scha 1981), at least as far as lexical (non-complex) predicates are involved (Winter 2001: Ch. 6). Meaning postulates need to be formulated in somewhat different ways depending on whether or not events are involved. In semantic frameworks that lack events, a meaning postulate for a distributive predicate like smile could state that whenever smile applies to a plurality of people, it also applies to each of them. In event semantics, a predicate like smile does not directly apply to the smilers, but to the associated smiling events instead. This raises the question of how best to formulate distributivity-related meaning postulates in event semantics.

I suggest that stratified reference is well-suited for this purpose because of the parameters it provides. Its dimension parameter can be set to "agent" in order to access the smilers via the smiling events. More generally, this parameter can be used to relativize the notion of distributivity to a given argument position. Predicates with multiple argument positions may be distributive on all, some, or none of these positions (Lasersohn 1988; Landman 1996). For example, the verb see is distributive on both its agent and theme positions, since it follows both from John and Mary saw Bill and from John saw Bill and Sue that John saw Bill. By contrast, the verb kill is distributive only on its theme role but not on its agent role, as the following scenario shows. The two outlaws Bonnie and Clyde were killed by a posse of six police officers, which included Sheriff Jordan. Given this background knowledge, (51a) entails (51b) but does not entail (51c). More generally, whenever a group of people is killed then each of them is killed, but a group of people can kill a person without it being the case that each of them kills that person.

(51) a. The police officers killed Bonnie and Clyde.

b. $\Rightarrow$ The police officers killed Bonnie.

c. $\nRightarrow$ Sheriff Jordan killed Bonnie and Clyde. 
I have shown in previous sections how the dimension parameter of stratified reference can be used to model the distinction between temporal and spatial foradverbials, and the different measure functions in pseudopartitives. For the present purpose, I propose to instantiate this parameter with different thematic roles. This is in keeping with the visual metaphor I introduced at the beginning of this paper, where a thematic role is just another dimension of the abstract space in which events live. We can see a (temporally) atelic predicate as a predicate that is distributive with respect to time. Similarly, we can see a distributive predicate as one that has stratified reference on the appropriate thematic position. I propose to capture lexical distributivity in event semantics by meaning postulates such as the following:

\section{(52) Meaning postulate: smile is distributive on its agent position}

$$
\begin{aligned}
& \operatorname{SR}_{\text {agent, } \operatorname{Atom}}(\lambda e . \operatorname{smile}(e)) \Leftrightarrow \\
& \forall e\left[\operatorname{smile}(e) \rightarrow e \in^{*} \lambda e^{\prime}\left(\begin{array}{l}
\operatorname{smile}\left(e^{\prime}\right) \wedge \\
\operatorname{Atom}\left(\operatorname{agent}\left(e^{\prime}\right)\right)
\end{array}\right)\right]
\end{aligned}
$$

(Every smiling event can be divided into one or more parts, each of which is a smiling event whose agent is atomic.)

This meaning postulate can be read as follows. Whenever there is a smiling event $e$, then that event consists of one or more smiling events $e^{\prime}$ whose agents are mereological atoms (that is, they have no proper parts). For example, if $e$ is an event in which John and Bill smile, then that event consists of two smiling events whose agents are atoms. From this, and from the assumption that John and Bill are atoms, it follows that John smiled and that Bill smiled.

We can capture the difference between the agent and theme role of kill by adopting a meaning postulate analogous to (52) only for the theme position of that verb and by refraining from adopting it for the agent position. In other words, distributivity on a given argument position is stratified reference on the dimension specified by the thematic role of that argument position.

Collective predicates, such as (be) numerous, (be a) couple, gather, meet, or hold hands, do not satisfy stratified reference on the thematic role of their subjects, because none of the atomic parts of these subjects participate in events that satisfy these predicates. For example, if John and Mary are a couple then it does not follow that John is a couple. This can be modeled by refraining from adopting distributivity meaning postulates for these predicates, or by adopting negated versions of these postulates.

However, it may still be useful to apply a modified form of such meaning postulates to a subset of collective predicates. The view of distributivity as 
stratified reference suggests that not only the dimension parameter but also the granularity parameter should have a role to play. This is indeed the case: it can be used to specify "how distributive" a given predicate is on a given argument position, for example whether it distributes all the way down to atoms or only to small but nonatomic entities.

Take for example the case of gather. Although this predicate is collective and not distributive, it still licenses entailments from larger to smaller numbers in ways that are reminiscent of a distributive predicate. For example, if A, B, and $\mathrm{C}$ gather, this entails that $\mathrm{A}$ and $\mathrm{B}$ gather, that $\mathrm{A}$ and $\mathrm{C}$ gather, and that $\mathrm{B}$ and $\mathrm{C}$ gather. More generally, the predicate gather licenses entailments from pluralities of cardinality $n$ to subpluralities of size $n-1, n-2$, and so on, down to 2. By contrast, other collective predicates, such as be numerous or be a good team, do not license this kind of entailment, since two people do not count as being numerous and since two people taken from a good team do not typically form a team by themselves (except when the good team consists of only these two people to begin with, as in tennis). These differences can be modeled by the granularity parameter of stratified reference. For example, gather satisfies the following meaning postulate (I use $|x|$ for the number of atomic parts of $x$ ):

\section{(53) Meaning postulate for gather}

$$
\begin{aligned}
& \operatorname{SR}_{\text {agent }, \lambda x \cdot|x|=2}(\lambda e \text {.gather }(e)) \Leftrightarrow \\
& \forall e\left[\operatorname{gather}(e) \rightarrow e \in^{*} \lambda e^{\prime}\left(\begin{array}{l}
\operatorname{gather}\left(e^{\prime}\right) \wedge \\
\left|\operatorname{agent}\left(e^{\prime}\right)\right|=2
\end{array}\right)\right]
\end{aligned}
$$

(Every gathering event can be divided into one or more parts, each of which is a gathering event whose agent is two people.)

The same kind of meaning postulate also holds of some other collective predicates, such as meet and hold hands. For example, if there is an event of ten people standing in a circle and holding hands, this event can be divided into parts in such a way that each part involves two people who stand next to each other. Each such part is then an event in which two people hold hands. Other collective predicates, such as be numerous and be a good team, do not satisfy this condition.

Kuhn (2014), building in part on Champollion (2010: Ch. 9), suggests that this distinction within the class of collective predicates might be linguistically relevant in connection with the behavior of the determiner all. As has often been observed, all rejects certain collective predicates, some of which involve cardinality checks, such as be numerous, be a group of five, or be a good team; but it is compatible with other collective predicates, some of which involve collective action, such as gather, meet, hold hands, and be similar (e.g. Kroch 1974; Dowty 1987; Moltmann 
1997). With respect to the first class, all patterns with distributive determiners such as each, a fact that justifies treating all as a distributive determiner, as shown in (54). With respect to the second class, however, all and each come apart, as shown in (55). I refer to this as the numerous-gather opposition. In the terminology of Winter (2001: Ch. 5), numerous-type predicates are grouped together with distributive predicates to form the category of "atom predicates", and gather-type predicates correspond to the category of "set predicates".

(54) a. *All the students who came to the rally are numerous.

b. ${ }^{\star}$ Each of the students who came to the rally is numerous.

(55) a. All the students \{met / gathered in the hallway / held hands\}.

b. `Each of the students \{met / gathered in the hallway / held hands\}.

This set of facts is just part of a more complex pattern of phenomena that involve the numerous-gather opposition, as described and analyzed in detail by Winter. First, the pattern can be generalized from all to strong quantifiers, as in (56). Second, the pattern breaks down for some speakers and predicates when the noun in question is replaced by a group noun (57).

(56) ${ }^{\star}$ Most of the students who came to the rally were numerous.

(57) All the groups of demonstrators were numerous.

Stratified reference helps capture the relevant semantic distinction involved between the two kinds of collective predicates illustrated above. I focus on (54) and (55) and I set aside (56) and (57) for the purpose of this paper. A full discussion and an extension of the present theory to the latter cases can be found in Champollion (2010: Ch. 9) and in Champollion (to appear(b)), as well as a comparison of the present theory with Winter's and other proposals.

I will build on the following basic idea. Distributive predicates have stratified reference down to atoms. Collective predicates like gather, meet, hold hands, and be similar are "almost distributive" in that they distribute down to entities of cardinality 2. That is, they have stratified reference with granularity parameter 2 , as stated in (53) for the case of gather. Other collective predicates like be numerous, be a group of five, or be the team that won the tournament are more similar to quantized predicates, in that they do not distribute down at all.

Suppose now that each and all impose stratified-reference requirements that are similar to those imposed by for-adverbials and pseudopartitives, but that they set their parameters in different ways. The dimension parameter is the 
relevant thematic role, and the granularity parameter is either set to Atom in the case of each, or to some low cardinality value in the case of all. That is, the two determiners have the entries in (58) and (59) and their presuppositions expand as in (60) and (61). I write *agent $(e)$ for the sum of the agents of the parts of $e$. I will reuse $\varepsilon$ as a placeholder for whatever turns out to be the granularity of all. (In the examples we have seen so far, there may be no need for the vagueness of $\varepsilon$, as we might simply set the threshold to cardinality 2 . But in the general case, a vague notion will be necessary since all can also combine with mass terms as in All the milk is sour, in which case cardinality is not an applicable notion, cf. Dobrovie-Sorin (2014).) Concretely, I will assume that $\varepsilon$ can combine with a set of numbers and with an entity (in this case, the type of $\varepsilon$ is $\langle n t, e t\rangle$ ), and that given this combination of arguments it checks whether the number of atomic parts of the entity is much smaller than the average of the numbers in the set. (In what follows, there will be only one number in the set, so the averaging step will turn out to be trivial.) The following entries are only adequate for the case where all or each occur in agent position and together with a plural count noun. In other cases, agent would need to be replaced by the appropriate thematic role, which could easily be modeled by abstracting over it. To account for the case in which all modifies a mass noun, $\varepsilon$ will need to be generalized appropriately. I will not do any of this here in order to keep the account simple.

(58) $\llbracket[$ each (of the) NP $] \rrbracket=$ $\lambda P \lambda e: \mathrm{SR}_{\text {agent, } \operatorname{Atom}}(P) \cdot\left[P(e) \wedge{ }^{*} \operatorname{agent}(e)=\oplus \mathrm{NP}\right]$

(59) $\llbracket[$ all the NP $] \rrbracket=$ $\lambda P \lambda e: \mathrm{SR}_{*}$ agent,,$(\lambda n . n=|\oplus \mathrm{NP}|)(P) .\left[P(e) \wedge{ }^{*} \operatorname{agent}(e)=\oplus \mathrm{NP}\right]$

(60) Presupposition of each:

$\forall e\left[\operatorname{VP}(e) \rightarrow e \in \epsilon^{*} \lambda e^{\prime}\left(\begin{array}{l}\operatorname{VP}\left(e^{\prime}\right) \wedge \\ \operatorname{Atom}\left(\operatorname{agent}\left(e^{\prime}\right)\right)\end{array}\right)\right]$

(Every VPing event $e$ consists of one or more VPing events whose agents are atoms.)

(61) Presupposition of all:

$\forall e\left[\operatorname{VP}(e) \rightarrow e \in \in^{*} \lambda e^{\prime}\left(\begin{array}{l}\mathrm{VP}\left(e^{\prime}\right) \wedge \\ \varepsilon(\lambda n . n=|\oplus \mathrm{NP}|)\left(\operatorname{agent}\left(e^{\prime}\right)\right)\end{array}\right)\right]$

(Every VPing event $e$ consists of one or more VPing events whose agents are very small in number compared to the number of atomic parts of the NP.) 
Given these assumptions, distributive predicates like smile as well as certain collective predicates (e.g. gather, hold hands) will satisfy the presupposition of all (Kuhn 2014). For example, when a group smiles, every one of its subgroups smiles, as does every one of its members; when a group gathers, every one of its subgroups gathers, though its individual members do not gather. For smile, this is shown in (62). For gather, this is shown in (63).

(62) all the children smiled

Satisfied presupposition: $\mathrm{SR}_{*}$ agent,$\varepsilon(\lambda n . n=\mid \oplus$ child $\mid)(\lambda e . \operatorname{smile}(e)) \Leftrightarrow$

$\forall e\left[\operatorname{smile}(e) \rightarrow e \in{ }^{*} \lambda e^{\prime}\left(\begin{array}{l}\operatorname{smile}\left(e^{\prime}\right) \wedge \\ \varepsilon(\lambda n . n=|\oplus \operatorname{child}|)\left({ }^{*} \operatorname{agent}\left(e^{\prime}\right)\right)\end{array}\right)\right]$

(Every smiling event can be divided into one or more parts, each of which is a smiling event whose agents are very small in number compared with the total number of children.)

(63) all the children gathered

Satisfied presupposition: $\mathrm{SR}_{*}$ agent,$\varepsilon(\lambda n . n=|\oplus \operatorname{child}|)(\lambda e$.gather $(e)) \Leftrightarrow$

$\forall e\left[\operatorname{gather}(e) \rightarrow e \in^{*} \lambda e^{\prime}\left(\begin{array}{l}\operatorname{gather}\left(e^{\prime}\right) \wedge \\ \varepsilon(\lambda n . n=|\oplus \operatorname{child}|)\left({ }^{*} \operatorname{agent}\left(e^{\prime}\right)\right)\end{array}\right)\right]$

(Every gathering event can be divided into one or more parts, each of which is a gathering event whose agents are very small in number compared with the total number of children.)

However, those collective predicates that do not have stratified reference down to any level will not satisfy the presupposition of all. Here is one example:

(64) *all the ants (in my kitchen) are numerous

Failed presupposition: $\operatorname{SR}_{*}$ participant,$\varepsilon(\lambda n . n=|\oplus \operatorname{ant}|)(\lambda e \cdot \operatorname{numerous}(e)) \Leftrightarrow$

$\forall e\left[\operatorname{numerous}(e) \rightarrow e \in{ }^{*} \lambda e^{\prime}\left(\begin{array}{l}\operatorname{numerous}\left(e^{\prime}\right) \wedge \\ \varepsilon(\lambda n . n=|\oplus \operatorname{ant}|)\left({ }^{*} \operatorname{participant}\left(e^{\prime}\right)\right)\end{array}\right)\right]$

(Every state of being numerous can be divided into one or more parts, each of which is a state of being numerous whose participants are very small in number compared with the total number of ants in my kitchen.)

As for each, only distributive predicates will satisfy its presupposition. Even a collective predicate that has stratified reference down to granularity level 2 , 
like meet, will not satisfy the more stringent granularity-level 1 requirement of each:

(65) *each of the children met

Failed presupposition: $\mathrm{SR}_{\text {agent,Atom }}(\lambda e \cdot \operatorname{meet}(e)) \Leftrightarrow$

$\forall e\left[\operatorname{meet}(e) \rightarrow e \in e^{*} \lambda e^{\prime}\left(\begin{array}{l}\operatorname{meet}\left(e^{\prime}\right) \wedge \\ \operatorname{Atom}\left(\operatorname{agent}\left(e^{\prime}\right)\right)\end{array}\right)\right]$

(Every meeting event can be divided into one or more parts, each of which is a meeting event whose agent is an atom.)

Stratified reference does not require that the predicate in question applies to all parts whose agent is small in the relevant way, only that there be some way of dividing the whole event into such parts. This nonexhaustive way in which stratified reference distributes the predicate is what allowed us to treat cases like five feet of snow. In the case of all, it predicts that there should be cases where not every small subevent is relevant. As noted by Kuhn (2014), this prediction is true:

(66) a. All the pieces of the puzzle fit together.

b. All the boys in the circle held hands.

In scenarios that make these sentences true, the predicates fit together and hold hands do not necessarily apply to all pairs, but only to pairs of adjacent pieces or boys. This is compatible with these predicates having stratified reference down to granularity level 2 .

To summarize this section, all is an "almost distributive" determiner: it requires distributivity down to a small granularity level, but not all the way down to atoms. Gather-type predicates are "a bit distributive"; numerous-type predicates are not. In keeping with the broader picture in Champollion (2010), the telic-atelic opposition can be formally related to the collective-distributive opposition. To explain why gather distinguishes between each and all, I have followed Kuhn (2014) in suggesting that each distributes over events with atomic individuals while all distributes over events whose agents must be small in number but need not be atomic.

A final remark on the notion that what sets gather-type predicates apart within the class of collective predicates is that they distribute down to elements of size 2. This basic idea is taken in essence from Kuhn (2014) and represents a slight departure from Champollion (2010), where I assumed instead that collective predicates technically never distribute and that gather-type-but not numerous-type-collective predicates have groups as agents, where groups are 
mereologically atomic entities that formally model plural individuals and that give rise to certain kinds of entailments about themselves involving collective action or collective responsibility (Landman 1989, 1996). The atomic nature of groups made sure that the stratified reference requirement was always vacuously satisfied. One problem with that view was that it did not capture the inferences from $A, B$, and $C$ gathered to $A$ and $B$ gathered. Another problem was that Landman and myself only gave a partial list of what constitutes collective entailments. What the present account has in common with Champollion (2010), however, is the idea that all imposes stratified reference just like each (though with different granularity parameter settings), and that both can therefore be seen as distributive items.

\section{Conclusion and outlook}

I have introduced a parametrized higher-order property, stratified reference, and used it to characterize a wide range of semantic oppositions: telic vs. atelic, singular vs. plural, count vs. mass, intensive vs. extensive, collective vs. distributive, and numerous-type collective vs. gather-type collective. I have claimed that stratified reference formalizes the bounded vs. unbounded opposition, which I have suggested as a way to subsume these semantic oppositions. Unboundedness corresponds to stratified reference, boundedness corresponds to lack of it. This has led to new answers to old questions, such as why for-adverbials reject telic predicates, why pseudopartitives reject singular count nouns and certain measure functions, and why each and (to some extent) all reject collective predicates. I have suggested that all these constructions impose a parametrized but otherwise identical requirement on one of their arguments, and that stratified reference is well suited to capture this requirement. In the rest of this paper, I sketch some broader implications of the present theory and connections to other domains of linguistics.

I have focused on characterizing the properties of predicates that typically consist of a single word. As for complex predicates (e.g. see thirty zebras), they too can be characterized as telic, atelic, distributive, collective, and so on. While stratified reference is useful for this purpose as well, a full account of aspect and distributivity in these cases will need to be complemented by a theory of how a given complex predicate ends up having or not having stratified reference.

For example, the distributive-collective opposition also applies to complex predicates such as wear a dress (distributive), share a pizza (collective), and carry the piano upstairs (mixed distributive/collective). Phrasal predicates like wear a dress can acquire distributivity through a covert VP-level distributivity operator whose meaning is a matter of debate. Either it distributes the predicate it modifies 
over atoms, similar to adverbial each (Link 1991; Winter 2001: Ch. 6), or it distributes them over salient nonatomic entities (Schwarzschild 1996: Ch. 5). Distributivity operators, whether covert or overt, can be reformulated in ways that are very similar to stratified reference. The difference between atomic and nonatomic distributivity can then be recast as a difference in settings of the granularity parameter of stratified reference (Champollion 2014a, 2014b). Certain overt modifiers, such as adverbial each and together, can also determine whether the predicate that they modify is understood distributively or collectively. Stratified reference allows us to think about the effect of each, together and distributivity operators and about aspectual composition as two sides of the same coin. The question of how complex predicates end up being collective or distributive is analogous to the question of how complex predicates end up being atelic or telic, a process also known as aspectual composition (e.g. Krifka 1998).

This also means that we can link problems that affect accounts of these processes. For example, certain apparently nonquantized predicates like eat something, eat less than three apples, and drink a quantity of wine empirically pattern with telic predicates, which present a challenge for algebraic accounts of aspect including mine (Zucchi and White 2001). Similarly, a number of collective predicates that are incompatible with all, such as be a group of less than five, would be expected to be compatible with all under the account I have discussed here (Kuhn 2014). I am not claiming to have a solution for these problems, only suggesting that if a solution to them in one domain emerges, we may well be able to adapt it to the other domain.

The overarching theme of this paper is the strengthening of semantic relationships and parallels that hold across the nominal and verbal domain. A natural question to ask is whether the common semantics I have suggested goes hand in hand with a common syntax. For example, the basic constituent structure of for-adverbials is generally accepted as something like [V [for [three hours]]]) where $\mathrm{V}$ is the label of the verbal projection that the for-adverbial modifies. But there is no consensus on the constituent structure of pseudopartitives. One possibility, which is in line with the intersective semantics of pseudopartitives I have assumed, is that the measure noun of a measure pseudopartitive forms a constituent with the determiner that precedes it, as in [[two pounds] [of tomatoes]] (Akmajian and Lehrer 1976; Guéron 1979; Gawron 2002; Schwarzschild 2002, 2006). An alternative to this analysis is the rightbranching structure [two [pounds [of tomatoes]]] (Stickney 2008; Bale 2009; Scontras 2014). It is also possible that the two structures correspond to two different readings (Landman 2004; Rothstein 2009). It would not be difficult to formulate the semantic account presented here in a way that is consistent with either structure. However, only the first structure is analogous to the 
for-adverbial and therefore reflects the semantic parallel between pseudopartitives and other distributive constructions.

The theory developed in this article is deeply connected with the algebraic semantic framework developed for the modeling of measuring-out and boundedness in Krifka (1998). Just like that framework, the present theory has potential applications in morphosyntax. For example, it may help explain how boundedness is marked by semantic case in Finnish (Krifka 1992; Kiparsky 1998), by perfective prefixes in Slavic (Filip 2000), and by accusative adverbials in Korean (Wechsler and Lee 1996).

Throughout this paper, I have assumed that singular count nouns are interpreted as involving reference to singular entities but not sums. This was necessary in order to explain the contrast between five pounds of books and ${ }^{*}$ five pounds of book, and it is justified in English by the corresponding contrast in numeral phrases (five books vs. ${ }^{*}$ five book). Other languages, like Hungarian and Turkish, require nouns to be morphologically singular when they combine with numerals, and also when they are used as substance nouns in pseudopartitives. From the point of view of the present theory, this leads to the view that singular nouns in these languages and constructions can be interpreted as involving reference to sums. Theories that adopt this view (Farkas and de Swart 2010; Bale et al. 2011) are compatible with the view developed here. This may be seen as an advantage for them over theories that reject this assumption (Ionin and Matushansky 2006).

While I have shown that the behavior of a large number of constructions can be reduced to one principle (sensitivity to stratified reference), the question arises why this principle exists and why these constructions are sensitive to it. In formal semantics, this is not the kind of question that is typically answered, or perhaps even answerable. There is no agreement on whether it even needs to be answered. On the one hand, for the purposes of comparing formal semantic theories to each other, formal semantics usually pays attention to something similar to Chomskyan explanatory adequacy: "If a number of highly complex and apparently unrelated facts are reducible to a few simple principles, then these principles explain these facts" (von Stechow 1984). On the other hand, we need not confine ourselves in this way: "we can seek a level of explanation deeper than explanatory adequacy, asking not only what the properties of language are but also why they are that way" (Chomsky 2001).

I do not know why there should be any constructions in language, let alone so many of them, that are sensitive to stratified reference or to the various properties it captures. To answer this question, it may be worth looking for explanations in domains other than formal semantics, such as first-language acquisition. Stratified reference may conceivably help first-language learners distinguish the functions of different constructions. For example, learners must distinguish constructions 
that specify the quantity of a substance or event, such as pseudopartitives, from superficially similar constructions that specify non-quantity-related properties, such as attributive constructions (three-pound strawberries). Attributive constructions do not impose stratified reference and are therefore compatible with intensive measure functions, as illustrated by three-degree water (Schwarzschild 2006). Apart from sometimes misinterpreting the number word in pseudopartitives as referring to cardinality of a relevant set of objects, four-year-olds tend to correctly distinguish pseudopartitives from attributives (Syrett 2013). Similarly, various studies have suggested that children are sensitive to the atelic-telic opposition as early as three years old, raising the question of how much of it is innately specified (Crain 2011). If something like the boundedness-unboundedness opposition is among the building blocks of the language faculty, then we might expect that children access it early on, and possibly that a child will learn different constructions that involve this building block at the same age.

Another kind of explanation, as well as another avenue for further research, may be found in linguistic theories that study conceptual linguistic knowledge and the mental patterns and representations in which it is organized, such as cognitive semantics (Talmy 2011) and conceptual semantics (Jackendoff 1996). The metaphor I have used to explain stratified reference, namely that individuals, substances, and events occupy regions in an abstract space whose dimensions include thematic roles and measure functions as well as spatial and temporal dimensions, is reminiscent of the theory of conceptual spaces in Gärdenfors (2007). The words that introduce stratified reference constraints, such as for, until, of, each and all, belong to closed-class categories such as prepositions and determiners. Cognitive semantics has found that closed-class categories are highly constrained in the range of conceptual categories they can express. The relevant conceptual category in this case would be boundedness. While cognitive semantics is sometimes seen as opposed to formal semantics, this does not have to be so (Krifka 1998; Zwarts and Verkuyl 1994). We can make use of formal semantic techniques such as the ones I have developed here, and assume that expressions are interpreted by elements of conceptual structures rather than entities in the real world. The present system may then be seen as a step towards a model-theoretic characterization of such frameworks.

Acknowledgments: A much longer presentation of this theory is offered in Champollion (2010, to appear (b)), a dissertation written at Penn, Stanford, and PARC. This paper was completed at New York University. I am grateful to all these institutions. Special thanks to my advisor, Cleo Condoravdi; my committee members, Aravind Joshi, Maribel Romero, Florian Schwarz; to Sigrid Beck, Danny Bobrow, Lauri Karttunen, Paul Kiparsky, Tony Kroch, Beth Levin, Chris Potts, Anna Szabolcsi, 
Annie Zaenen, Ziren Zhou; to the participants of my mereology seminar at New York University in 2013 and 2014; to Manfred Krifka, for encouraging me to write this paper; to him and Hans-Martin Gärtner, for their help as editors; to an anonymous reviewer, who provided helpful and detailed suggestions; and to many others who helped me write the dissertation, too numerous to list here.

\section{List of symbols used}

$\varepsilon \quad$ a predicate that encodes what it means to be very small

$\mu \quad$ a measure function

$\sigma \quad$ the spatial extent function

$\tau \quad$ the runtime function ("temporal trace")

$\oplus \quad$ the mereological sum operator

$\leq \quad$ mereological parthood

* the algebraic closure operator

$|x| \quad$ the number of atomic parts of $x$

\section{References}

Akmajian, Adrian \& Adrienne Lehrer. 1976. NP-like quantifiers and the problem of determining the head of an NP. Linguistic Analysis 2(4). 395-413.

Bach, Emmon. 1986. The algebra of events. Linguistics and Philosophy 9(1). 5-16. http://dx.doi.org/10.1007/bf00627432.

Bale, Alan. 2009. Yet more evidence for the emptiness of plurality. In A. Schardl, M. Walkow \& M. Abdurrahman (eds.), Proceedings of the 38th Annual Meeting of the North Eastern Linguistics Society (NELS 38), vol. 1, 75-88. Graduate Linguistics Student Association. Amherst, MA: University of Massachussetts.

Bale, Alan, Michaël Gagnon \& Hrayr Khanjian. 2011. Cross-linguistic representations of numerals and number marking. In N. Li \& D. Lutz (eds.), Proceedings of the 20th Conference on Semantics and Linguistic Theory (SALT 20), 582-598. CLC Publications. http://dx.doi.org/10.3765/salt.v20i0.2552.

Bennett, Michael R. \& Barbara H. Partee. 1972. Toward the logic of tense and aspect in English. Tech. rep. System Development Corporation.

Champollion, Lucas. 2010. Parts of a whole: Distributivity as a bridge between aspect and measurement. Philadelphia, PA: University of Pennsylvania Dissertation. http://repository.upenn.edu/edissertations/958/.

Champollion, Lucas. 2014a. Covert distributivity in algebraic event semantics. Under revision. http://ling.auf.net/lingbuzz/002097.

Champollion, Lucas. 2014b. Overt distributivity in algebraic event semantics. Under revision. http://ling.auf.net/lingbuzz/002098.

Champollion, Lucas. to appear(a). Distributivity, collectivity and cumulativity. In L. Matthewson, C. Meier, H. Rullmann \& T. E. Zimmermann (eds.), Wiley's companion to semantics. Hoboken, NJ: Wiley. http://ling.auf.net/lingbuzz/002133. 
Champollion, Lucas. to appear(b). Parts of a whole: Distributivity as a bridge between aspect and measurement. Oxford: Oxford University Press.

Champollion, Lucas \& Manfred Krifka. to appear. Mereology. In P. Dekker \& M. Aloni (eds.), Cambridge handbook of semantics. Cambridge University Press. http://ling.auf.net/lingbuzz/002099.

Chomsky, Noam. 2001. Beyond explanatory adequacy. MIT Occasional Papers in Linguistics 20. 104-131.

Crain, Stephen. 2011. Meaning in first language acquisition. In K. von Heusinger, C. Maienborn \& P. Portner (eds.), Semantics: An international handbook of natural language meaning, vol. 3 Handbücher zur Sprach- und Kommunikationswissenschaft / Handbooks of Linguistics and Communication Science (HSK), chap. 103, 2724-2752. Berlin, Germany/ Boston, MA: de Gruyter. http://dx.doi.org/10.1515/9783110253382.2724.

Daubert, B. F. \& T. H. Clarke. 1944. Unsaturated Synthetic Glycerides. VI. Polymorphism of Symmetrical Monoöleyldisaturated Triglycerides. Journal of the American Chemical Society 66(5). 690-691. http://dx.doi.org/10.1021/ja01233a008.

Dobrovie-Sorin, Carmen. 2014. Collective quantification and the homogeneity constraint. In M. Wiegand, T. Snider \& S. D’Antonio (eds.), Proceedings of the 24th Conference on Semantics and Linguistic Theory (SALT 24), 453-472. LSA and CLC Publications. http://dx.doi.org/10.3765/salt.v24i0.2428.

Doetjes, Jenny. 2007. Adverbs and quantification: Degrees versus frequency. Lingua 117(4). 685-720. http://dx.doi.org/10.1016/j.lingua.2006.04.003.

Dowty, David R. 1979. Word meaning and Montague grammar: The semantics of verbs and times in generative semantics and in Montague's PTQ, vol. 7 Studies in Linguistics and Philosophy. Dordrecht, Netherlands: Reidel. http://dx.doi.org/10.1007/978-94-009-9473-7.

Dowty, David R. 1987. Collective predicates, distributive predicates, and All. In F. Marshall (ed.), Proceedings of the 3rd Eastern States Conference on Linguistics (ESCOL 3), 97-115. Columbus, $\mathrm{OH}$ : The Ohio State University.

Farkas, Donka F. \& Henriëtte E. de Swart. 2010. The semantics and pragmatics of plurals. Semantics and Pragmatics 3(6). 1-54. http://dx.doi.org/10.3765/sp.3.6.

Filip, Hana. 2000. The quantization puzzle. In C. L. Tenny \& J. Pustejovsky (eds.), Events as grammatical objects: the converging perspectives of lexical semantics and syntax, 39-96. Stanford, CA: CSLI Publications.

Gärdenfors, Peter. 2007. Representing actions and functional properties in conceptual spaces. In T. Ziemke, J. Zlatev \& R. M. Frank (eds.), Body language and mind, volume 1: Embodiment, 167-196. Berlin, Germany: Mouton de Gruyter. http://dx.doi.org/10.1515/ 9783110207507.2.167.

Gawron, Jean Mark. 2002. Two kinds of determiners in DP. Talk at LSA winter meeting.

Gawron, Jean Mark. 2005. Generalized paths. In E. Georgala \& J. Howell (eds.), Proceedings of the 15th Conference on Semantics and Linguistic Theory (SALT 15). Ithaca, NY: CLC Publications. http://www-rohan.sdsu.edu/ gawron/salt_paper.pdf.

Groenendijk, J., T. Janssen \& M. Stokhof (eds.). 1984. Truth, interpretation and information: Selected papers from the Third Amsterdam Colloquium. Dordrecht, Netherlands: Foris. http://dx.doi.org/10.1515/9783110867602.

Guéron, Jacqueline. 1979. On the structure of "pseudo-partitive” NP's. Bulletin of the ICU Summer Institute in Linguistics 12. 21-48.

Heim, Irene \& Angelika Kratzer. 1998. Semantics in generative grammar. Oxford, UK: Blackwell Publishing. 
Hinrichs, Erhard. 1985. A compositional semantics for Aktionsarten and NP reference in English. Columbus, $\mathrm{OH}$ : Ohio State University Dissertation. http://rave.ohiolink.edu/etdc/view? acc_num=osu1272461401.

Hitzeman, Janet. 1991. Aspect and adverbials. In S. K. Moore \& A. Z. Wyner (eds.), Proceedings of the 1st Conference on Semantics and Linguistic Theory (SALT 1), 107-126. Ithaca, NY: Cornell University. http://dx.doi.org/10.3765/salt.v1i0.2763.

Hitzeman, Janet. 1997. Semantic partition and the ambiguity of sentences containing temporal adverbials. Natural Language Semantics 5(2). 107-126. http://dx.doi.org/10.1023/ a:1008221528793.

Ionin, Tania \& Ora Matushansky. 2006. The composition of complex cardinals. Journal of Semantics 23(4). 315-360. http://dx.doi.org/10.1093/jos/ffl006.

Jackendoff, Ray S. 1996. The proper treatment of measuring out, telicity, and perhaps even quantification in English. Natural Language and Linguistic Theory 14(2). 305-354. http://dx.doi.org/10.1007/bf00133686.

Karttunen, Lauri. 1974. Until. In Papers from the 10th regional meeting of the Chicago Linguistic Society (CLS 10), 283-297. Chicago, IL. http://web.stanford.edu/ laurik/publications/ archive/until.pdf.

Kiparsky, Paul. 1998. Partitive case and aspect. In M. Butt \& W. Geuder (eds.), The projection of arguments: Lexical and compositional factors, 265-307. Stanford, CA: CSLI Publications.

Krantz, David H., R. Duncan Luce, Patrick Suppes \& Amos Tversky. 1971. Foundations of measurement. New York, NY: Academic Press.

Kratzer, Angelika. 2007. On the plurality of verbs. In J. Dölling, T. Heyde-Zybatow \& M. Schäfer (eds.), Event structures in linguistic form and interpretation, 269-300. Berlin, Germany: de Gruyter. http://dx.doi.org/10.1515/9783110925449.269.

Krifka, Manfred. 1986. Nominalreferenz und Zeitkonstitution: Zur Semantik von Massentermen, Pluraltermen und Aspektklassen. Munich, Germany (published 1989): Wilhelm Fink. http://amor.cms.hu-berlin.de/ h2816i3x/Publications/Krifka_1989_Nominalreferenz_ Zeitkonstitution.PDF.

Krifka, Manfred. 1989. Nominal reference, temporal constitution and quantification in event semantics. In R. Bartsch, J. van Benthem \& P. van Emde Boas (eds.), Semantics and contextual expression, 75-115. Dordrecht, Netherlands: Foris.

Krifka, Manfred. 1992. Thematic relations as links between nominal reference and temporal constitution. In I. A. Sag \& A. Szabolcsi (eds.), Lexical matters, 29-53. Stanford, CA: CSLI Publications.

Krifka, Manfred. 1998. The origins of telicity. In S. Rothstein (ed.), Events and grammar, vol. 70 Studies in Linguistics and Philosophy, 197-235. Dordrecht, Netherlands: Kluwer. http://dx.doi.org/10.1007/978-94-011-3969-4_9.

Kroch, Anthony S. 1974. The semantics of scope in English. Cambridge, MA: Massachusetts Institute of Technology Dissertation. http://dspace.mit.edu/handle/1721.1/13020.

Kuhn, Jeremy. 2014. Gather-type predicates: massiness over participants. Presentation at the 45th Meeting of the North East Linguistic Society (NELS 45). http://www.jeremykuhn.net/ papers/Kuhn-gather-slides.pdf.

Landman, Fred. 1989. Groups, I. Linguistics and Philosophy 12(5). 559-605. http://dx.doi.org/ $10.1007 / \mathrm{bf00627774.}$

Landman, Fred. 1996. Plurality. In S. Lappin (ed.), Handbook of contemporary semantic theory, 425-457. Oxford, UK: Blackwell Publishing. 
Landman, Fred. 2004. Indefinites and the type of sets. Oxford, UK: Blackwell Publishing. http://dx.doi.org/10.1002/9780470759318.

Lasersohn, Peter. 1988. A semantics for groups and events. Columbus, $\mathrm{OH}$ : Ohio State University Dissertation.

Link, Godehard. 1983. The logical analysis of plurals and mass terms: A lattice-theoretical approach. In Reiner Bäuerle, Christoph Schwarze \& Arnim von Stechow (eds.), Meaning, use and interpretation of language, 303-323. Berlin, Germany: de Gruyter. http://dx.doi.org/10.1515/9783110852820.302. Reprinted in Link (1998), Chapter 1.

Link, Godehard. 1991. Quantity and number. In D. Zaefferer (ed.), Semantic universals and universal semantics, 133-149. Dordrecht, Netherlands: Foris. Reprinted in Link (1998), Chapter 9.

Link, Godehard. 1998. Algebraic semantics in language and philosophy. Stanford, CA: CSLI Publications. http://standish.stanford.edu.

Mills, I., T. Cvitaš, K. Homann, N. Kallay \& K. Kuchitsu (eds.). 2007. Quantities, units and symbols in physical chemistry (IUPAC Green Book). Oxford, UK: Blackwell Science. http://dx.doi.org/10.1039/9781847557889.

Mollá-Aliod, Diego. 1997. Aspectual composition and sentence interpretation: A formal approach. Edinburgh, UK: University of Edinburgh dissertation. http://comp.mq.edu.au/ $\sim$ diego/publications/phd/thesis.ps.gz.

Moltmann, Friederike. 1991. Measure adverbials. Linguistics and Philosophy 14(6). 629-660. http://dx.doi.org/10.1007/bf00631962.

Moltmann, Friederike. 1997. Parts and wholes in semantics. Oxford: Oxford University Press.

Parsons, Terence. 1987. Underlying states in the semantical analysis of English. In Proceedings of the Aristotelian society, vol. 88, 13-30. http://www.jstor.org/stable/4545070.

Rothstein, Susan. 2009. Individuating and measure readings of classifier constructions: Evidence from Modern Hebrew. Brill's Journal of Afroasiatic Languages and Linguistics 1(1). 106-145. http://dx.doi.org/10.1163/187666309x12491131130783.

Scha, Remko. 1981. Distributive, collective and cumulative quantification. In J. Groenendijk, T. Janssen \& M. Stokhof (eds.), Formal methods in the study of language, Amsterdam, Netherlands: Mathematical Center Tracts. http://dx.doi.org/10.1515/9783110867602.131. Reprinted in Groenendijk et al. (1984), pages 131-158.

Schwarzschild, Roger. 1996. Pluralities, vol. 61 Studies in Linguistics and Philosophy. Dordrecht, Netherlands: Kluwer. http://dx.doi.org/10.1007/978-94-017-2704-4.

Schwarzschild, Roger. 2002. The grammar of measurement. In B. Jackson (ed.), Proceedings of the 12th Conference on Semantics and Linguistic Theory (SALT 12), Cornell University. Ithaca, NY: CLC Publications. http://dx.doi.org/10.3765/salt.v12i0.2870.

Schwarzschild, Roger. 2006. The role of dimensions in the syntax of noun phrases. Syntax 9(1). 67-110. http://dx.doi.org/10.1111/j.1467-9612.2006.00083.x.

Scontras, Gregory. 2014. The semantics of measurement: Harvard University dissertation. http://web.stanford.edu/ scontras//papers/Scontras_Thesis.pdf.

Selkirk, Lisa. 1977. Some remarks on noun phrase structure. In P. Culicover, T. Wasow \& A. Akmajian (eds.), Formal syntax, 285-316. New York, NY: Academic Press.

von Stechow, Arnim. 1984. Comparing semantic theories of comparison. Journal of Semantics 3(1-2). 1-77. http://dx.doi.org/10.1093/jos/3.1-2.1.

von Stechow, Arnim. 2002. German seit 'since' and the ambiguity of the German perfect. In I. Kaufmann \& B. Stiebels (eds.), More than words. A Festschrift for Dieter Wunderlich, 393-432. Berlin, Germany: Akademie Verlag. http://dx.doi.org/ 10.1515/9783050081274-016. 
Stickney, Helen. 2008. The emergence of DP in the partitive structure. Amherst, MA: University of Massachusetts Dissertation. http://scholarworks.umass.edu/dissertations/ AAl3380028.

Syrett, Kristen. 2013. The role of cardinality in the interpretation of measurement expressions. Language Acquisition 20(3). 228-240. http://dx.doi.org/10.1080/10489223.2013.796949.

Talmy, Leonard. 2011. Cognitive semantics: An overview. In K. von Heusinger, C. Maienborn \& P. Portner (eds.), Semantics: An international handbook of natural language meaning, vol. 1 Handbücher zur Sprach- und Kommunikationswissenschaft / Handbooks of Linguistics and Communication Science (HSK), chap. 27, 622-642. de Gruyter. http://dx.doi.org/10.1515/9783110226614.622.

Taylor, Barry. 1977. Tense and continuity. Linguistics and Philosophy 1(2). 199-220. http://dx.doi.org/10.1007/bf00351103.

Vendler, Zeno. 1957. Verbs and times. The Philosophical Review 66(2). 143-160. http://dx.doi.org/10.2307/2182371.

Wechsler, Stephen \& Yae-Sheik Lee. 1996. The domain of direct case assignment. Natural Language and Linguistic Theory 14(3). 629-664. http://dx.doi.org/10.1007/bf00133600.

Winter, Yoad. 2001. Flexibility principles in Boolean semantics: The interpretation of coordination, plurality, and scope in natural language. Cambridge, MA: MIT Press.

Zucchi, Sandro \& Michael White. 2001. Twigs, sequences and the temporal constitution of predicates. Linguistics and Philosophy 24(2). 187-222. http://dx.doi.org/10.1023/ a:1005690022190.

Zwarts, Joost. 2006. Event shape: Paths in the semantics of verbs. Manuscript. Radboud University Nijmegen and Utrecht University. http://www.let.uu.nl/users/Joost. Zwarts/personal/EventShape.pdf.

Zwarts, Joost \& Henk J. Verkuyl. 1994. An algebra of conceptual structure: an investigation into Jackendoff's conceptual semantics. Linguistics and Philosophy 17(1). 1-28. http://dx.doi.org/10.1007/bf00985039 